\title{
The Power State Estimation Method for High Energy Ternary Lithium-ion Batteries Based on the Online Collaborative Equivalent Modeling and Adaptive Correction - Unscented Kalman Filter
}

\author{
Yongcun Fan ${ }^{1}$, Shunli Wang ${ }^{1, *}$, Cong Jiang ${ }^{1}$, Carlos Fernandez ${ }^{2}$ \\ ${ }^{1}$ School of Information Engineering, Southwest University of Science and Technology, Mianyang, \\ 621010, China \\ ${ }^{2}$ School of Pharmacy and Life Sciences, Robert Gordon University, Aberdeen AB17GJ, UK. \\ *E-mail: 497420789@qq.com
}

doi: $10.20964 / 2021.01 .70$

Received: 19 September 2020 / Accepted: 5 November 2020 / Published: 30 November 2020

\begin{abstract}
Accurate power state estimation plays an important role in the real-time working state monitoring and safety control of high energy lithium-ion batteries. To solve the difficulty and low accuracy problems in its real-time power state estimation under various operating conditions, the working characteristics of the lithium cobalt oxide batteries are analyzed comprehensively under various operating conditions. An improved collaborative equivalent model is established to characterize its working characteristics and then the initial power state value is calibrated by using the experimental relationship between open circuit voltage and state of charge considering the importance of the precious estimation accuracy for the later iterate calculation and correction. And then, an adaptive correction - Unscented Kalman Filter algorithm is put forward and applied for the state of charge estimation and output voltage tracking so as to realize the real-time high-precision lithium-ion battery power state estimation. The experimental results show that the established model can predict the power state of high energy lithium-ion batteries conveniently with high convergency speed within 30 seconds, accurate output voltage tracking effect within $32 \mathrm{mV}$ and high accuracy, the max estimation error of which is $3.87 \%$, providing an effective working state monitoring and safety protection method in the cleaner production and power supply processes of the high energy lithium-ion batteries.
\end{abstract}

Keywords: high energy lithium-ion battery; collaborative equivalent model; power state estimation; adaptive correction - Unscented Kalman Filter; output voltage tracking 
(C) 2021 The Authors. Published by ESG (www.electrochemsci.org). This article is an open access article distributed under the terms and conditions of the Creative Commons Attribution license (http://creativecommons.org/licenses/by/4.0/). 